\title{
Ferrite Formation Behaviors from B1 Compounds in Steels
}

\author{
Changjoon LEE, Shoichi NAMBU, Junya INOUE and Toshihiko KOSEKI \\ Department of Materials Engineering, The University of Tokyo, Tokyo, 113-8656 Japan. E-mail: lee@metall.t.u-tokyo.ac.jp
}

(Received on April 28, 2011; accepted on May 18, 2011)

\begin{abstract}
The effect of chemical composition of B1 compounds on the formation of intragranular ferrite during isothermal austenite-to-ferrite transformation was investigated by embedding single crystalline grains of chemically pure B1 compounds in low-alloy steel. Two kinds of B1 compounds having similar misfit against ferrite, $\mathrm{TiO}$ and $\mathrm{TiN}$, were adopted in this study. Isothermal transformation experiments were carried out both above and below the bainitic transformation temperature. The orientation relationships between compound and ferrite and between ferrite and prior austenite were characterized by scanning electron microscope equipped with electron backscatter diffraction analyzer.

It was found that the Baker-Nutting (B-N) orientation relationship played a dominant role in ferrite formation from B1 compounds at higher transformation temperature, but some low-index orientation relationships other than the Baker-Nutting orientation relationship were also observed as the transformation temperature decreased, which led to an increase in ferrite formation having the Kurdjumov-Sachs (K-S) orientation relationship with prior austenite. Ferrites from TiO had larger misorientation angles from the exact B-N orientation relationship and thus tended to have the K-S orientation relationship with prior austenite at lower transformation temperatures.
\end{abstract}

KEY WORDS: intragranular ferrite; acicular ferrite; B1 compounds; Baker-Nutting orientation relationship; Kurdjumov-Sachs orientation relationship.

\section{Introduction}

As a key concept to improve properties of weld metals and coarse-grained heat affected zone (CG-HAZ) of low alloy steel, intragranular ferrite nucleated from inclusions has attracted much attention, owing to its capability to improve toughness by forming high angle boundaries inside prior austenite grains. ${ }^{1,2}$ Thus, a number of experiments have been conducted to clarify the chemical nature of inclusions and mechanism that are responsible to the formation of the intragranular ferrite. ${ }^{3-6)}$ Among others, B1(NaCl)type oxides and nitrides have attracted much attention because they have a crystal orientation relationship with low lattice mismatch with ferrite, the so-called Baker-Nutting (B-N) orientation relationship, i.e., $\left((001)_{\alpha} / /(001)_{\mathrm{B} 1},[110]_{\alpha} / /\right.$ $\left.[100]_{\mathrm{B} 1}\right) .^{7-10)}$ The inclusions found in those studies, however, are usually composed of many phases, which prevents us from identifying particular phases and mechanisms effective to the formation of the intragranular ferrite. In order to overcome the difficulty, a new experimental setup, in which chemically pure compounds are pressure-bonded to steel, has been utilized to create interfaces as nucleation sites for ferrite.

Using the technique, several studies have clarified the noticeable effect of chemistry of B1 compounds on the ferrite formation behavior for different transformation temperatures. For instance, after isothermal experiments at $510^{\circ} \mathrm{C}$, Gregg and Bhadeshia reported that ferrites were nucleated only on $\mathrm{TiO}$ but not on TiN, ${ }^{7)}$ while at higher temperatures, $670-730^{\circ} \mathrm{C}$, Zhang et al. reported that $\mathrm{TiO}$ had inferior fer- rite nucleation ability to $\mathrm{TiN} .{ }^{8)}$ In addition to the temperature dependency of potential of B1 compound for promoting ferrite formation, Kasai et al. recently clarified from the continuous cooling experiments conducted above the bainite formation temperature the chemistry effect on the orientation relationship between B1 compounds and ferrite nucleated there. It was reported that most of ferrites nucleated on TiN particles hold more strictly B-N orientation relationship with the substrate compound than those nucleated on TiO particles, and the result was explained by electron bonding behaviors at the interface between B1 compounds and ferrite through the application of the first-principle calculation. ${ }^{11)}$

In this study, interest was focused on orientation relationship between B1 compounds and ferrite to understand the effect of chemistry of B1 compounds on the temperature dependence of ferrite transformation behavior from B1 compounds.

\section{Experimental Procedure}

The composition of the steel used for this study is shown in Table 1. The steel was shaped into rods of $8 \mathrm{~mm}$ diameter and $5 \mathrm{~mm}$ height. Among $\mathrm{B} 1$ compounds, $\mathrm{TiO}$ and $\mathrm{TiN}$, which have similar lattice parameters, were used to exclude the effect of lattice matching. Lattice parameters of ferrite and B1 compounds used in this study and misfits between the $\mathrm{B} 1$ compounds and ferrite were listed in Table 2 . In fact, TiO has either of $\mathrm{B} 1(\mathrm{NaCl})$ structure $(\mathrm{a}=4.18 \AA)$ or monoclinic structure $\left(a=5.86 \AA, b=9.34 \AA, 4.14 \AA, \gamma=107.3^{\circ}\right)$ at the 
Table 1. Composition of the steel used in this study.

\begin{tabular}{cccccc}
\hline $\mathrm{C}$ & $\mathrm{Si}$ & $\mathrm{Mn}$ & $\mathrm{P}$ & $\mathrm{S}$ & $\mathrm{B}$ \\
\hline 0.20 & 0.25 & 1.41 & 0.014 & 0.004 & 0.009 \\
\hline
\end{tabular}

Table 2. Lattice parameters of ferrite and $B 1$ compounds used in this study and misfits between the B1 compounds and ferrite.

\begin{tabular}{rcc}
\hline & Lattice constant $(\AA)$ & Misfit with ferrite \\
\hline $\mathrm{TiO}$ & 4.18 & $3.0 \%$ \\
$\mathrm{TiN}$ & 4.24 & $4.5 \%$ \\
bcc Fe & 2.87 & - \\
\hline
\end{tabular}

temperatures below $990^{\circ} \mathrm{C}$. However the monoclinic structure has a pseudo-cubic unit cell $\left(\mathrm{a}^{\prime}=4.20 \AA, \mathrm{b}^{\prime}=4.14 \AA\right.$, $\left.c^{\prime}=4.14 \AA, \gamma=89.9^{\circ}\right)$ which is very similar to $\mathrm{B} 1$ structure, having $2.8 \%$ misfit with ferrite. ${ }^{12)}$ Thus, considering the similarity of these two structures, TiO was assumed to have B1 structure in this study. To gain easy access to the investigation of crystal orientation relationships with ferrite, the B1 compounds used were in the form of single crystalline grains with size distribution in the range of 5-40 $\mu \mathrm{m}$ and 1$15 \mu \mathrm{m}$ for $\mathrm{TiO}$ and $\mathrm{TiN}$, respectively.

The single crystalline grains of $\mathrm{TiO}$ and $\mathrm{TiN}$ were inserted between two steel rods and the rods were then hotpressed to each other at $1050^{\circ} \mathrm{C}$. The specimens were reheated at $1050^{\circ} \mathrm{C}$ for austenitization of the steel and held for $15000 \mathrm{~s}$ so that the austenite grains grew and the single crystalline grains of B1 compounds were embedded inside the austenite grains. Subsequently, the specimen was cooled down to $500^{\circ} \mathrm{C}, 600^{\circ} \mathrm{C}$ or $650^{\circ} \mathrm{C}$ at the cooling rate of $50^{\circ} \mathrm{C} / \mathrm{s}$ and held at those temperatures for 10-200 s. Lastly, the specimen was gas quenched to room temperature at the cooling rate of $50^{\circ} \mathrm{C} / \mathrm{s}$. Additionally, an experiment to quench the sample just after holding at $1050^{\circ} \mathrm{C}$ was executed.

The heat-treated specimens were sectioned along the direction normal to the interface between two steel rods. They were etched in $2 \%$ nital after mechanically polished using $\mathrm{SiC}$ papers and $1 \mu \mathrm{m}, 0.06 \mu \mathrm{m}$ alumina powder. Scanning electron microscopy (SEM), Energy dispersive X-ray spectroscopy (EDS) and electron backscattering diffraction (EBSD) were employed to analyze the specimens. Ferrites which nucleated from $\mathrm{TiO}$ and $\mathrm{TiN}$ with size larger than $1 \mu \mathrm{m}$ were investigated by EBSD and the numbers of ferrites from $\mathrm{TiO}$ which were investigated by EBSD were 21, 80 and 66 at $650^{\circ} \mathrm{C}, 600^{\circ} \mathrm{C}$ and $500^{\circ} \mathrm{C}$, respectively, while 14,50 and 50 ferrites from TiN were investigated at $650^{\circ} \mathrm{C}$, $600^{\circ} \mathrm{C}$ and $500^{\circ} \mathrm{C}$, respectively.

\section{Results and Discussion}

\subsection{Ferrite Formation from B1 Compounds}

From EDS analysis, any formation of oxide, nitride or carbide was not observed around the B1 compounds. Mn depletion was not identified either. In addition, any apparent change of chemical composition or crystal structure of B1 compounds during heat treatments was evidenced either through EBSD analysis.

Optical micrographs of specimens quenched from $1050^{\circ} \mathrm{C}$ to room temperature were shown in Fig. 1, which

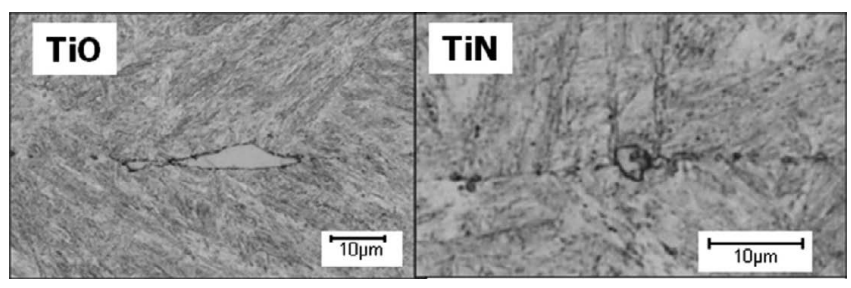

Fig. 1. Optical microscopic images of specimens quenched after austenitized at $1050^{\circ} \mathrm{C}$ for $15000 \mathrm{~s}$. No ferrites formed during quenching process were observed.

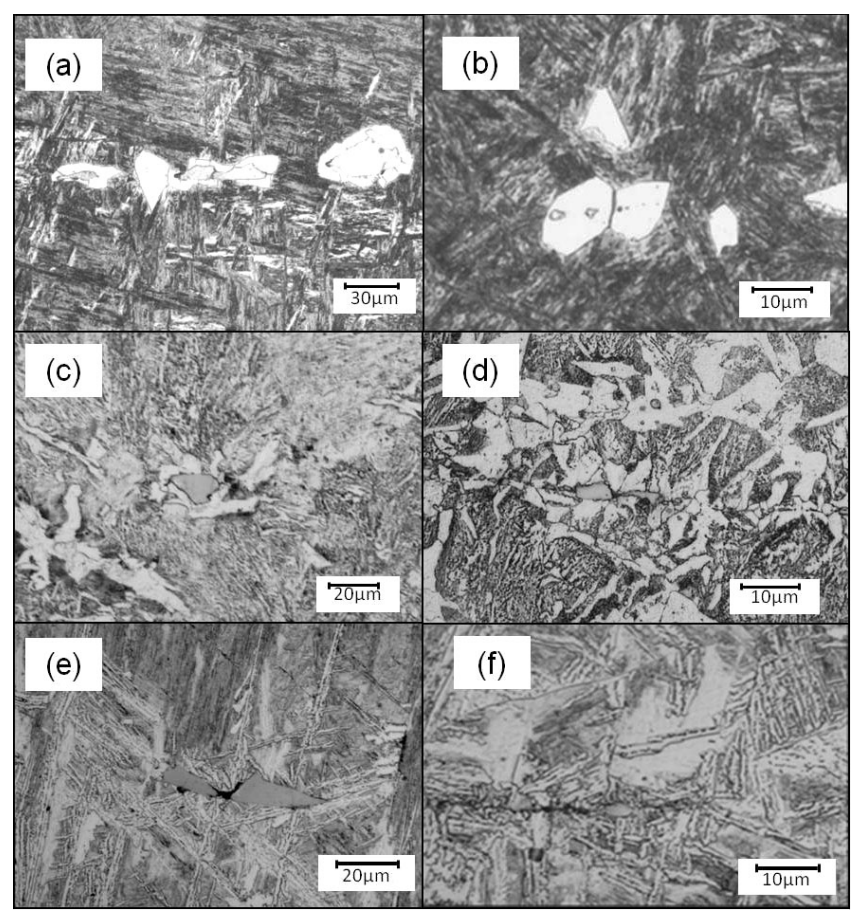

Fig. 2. Optical microscopic images of specimens isothermally held (a) at $650^{\circ} \mathrm{C}$ with $\mathrm{TiO}$ (b) at $650^{\circ} \mathrm{C}$ with $\mathrm{TiN}$ (c) at $600^{\circ} \mathrm{C}$ with $\mathrm{TiO}(\mathrm{d})$ at $600^{\circ} \mathrm{C}$ with $\mathrm{TiN}$ (e) at $500^{\circ} \mathrm{C}$ with $\mathrm{TiO}(\mathrm{f})$ at $500^{\circ} \mathrm{C}$ with $\mathrm{TiN}$.

clearly indicate that ferrite was not formed from B1 compounds during the quenching process.

Both $\mathrm{TiO}$ and $\mathrm{TiN}$ showed very good ferrite formation capability at temperatures of interest, while the shape of the ferrite from B1 compounds was changed as the transformation temperature decreased. As the result of isothermal holding at $650^{\circ} \mathrm{C}$ for $200 \mathrm{~s}$, polygonal ferrites were observed to nucleate from the entire surface of $\mathrm{TiO}$ and $\mathrm{TiN}$ as shown in Figs. 2(a) and 2(b), respectively. It is seen that the formation of ferrites from B1 compounds was faster than that from prior austenite grain boundaries. After isothermal holding at $600^{\circ} \mathrm{C}$ for $200 \mathrm{~s}$ Figs. 2(c) and 2(d), more plate shaped ferrites were formed as compared to the sample prepared at $650^{\circ} \mathrm{C}$. After isothermal holding at $500^{\circ} \mathrm{C}$ for $20 \mathrm{~s}$, it was observed that ferrites were nucleated from almost the entire surface of $\mathrm{TiO}$ and $\mathrm{TiN}$ as shown in Figs. 2(e) and 2(f), respectively and more acicular ferrites were observed around TiO than TiN.

\subsection{Orientation Relationship between B1 Compound and Ferrite}

Crystal orientations of ferrites nucleated from B1 compounds were investigated by EBSD to clarify orientation 
relationship between ferrite and B1 compounds. In this study, all the pole figures are plotted using the crystal axes of $\mathrm{B} 1$ compounds, $<001>_{\mathrm{B} 1}$, as the reference frame, RD, TD, and ND, instead of the sample axes, so that we can easily identify the orientation relationship between ferrite and B1 compounds. For instance, if a ferrite and a B1 compound have the $\mathrm{B}-\mathrm{N}$ orientation relationship with a misorientation angle less than 15 degrees, all of the three $\{001\} \alpha$ poles of the ferrite must fall into the circles shown in Fig. 3(a). Likewise, low index orientation relationships other than the B-N orientation relationship can be identified and the typical pole figures of ferrites with low-index orientation relationships, other than the B-N orientation relationship, are shown in Figs. 3(b)-3(d).

Figure 4(a) shows the proportion of B-N orientation relationship described by a number fraction of ferrites having B$\mathrm{N}$ orientation relationship with a misorientation angle less than 15 degrees out of those supposed to nucleate from B1 compounds at $650^{\circ} \mathrm{C}$. It is clear that more than $70 \%$ of ferrites had the $\mathrm{B}-\mathrm{N}$ orientation relationship both with $\mathrm{TiO}$ and

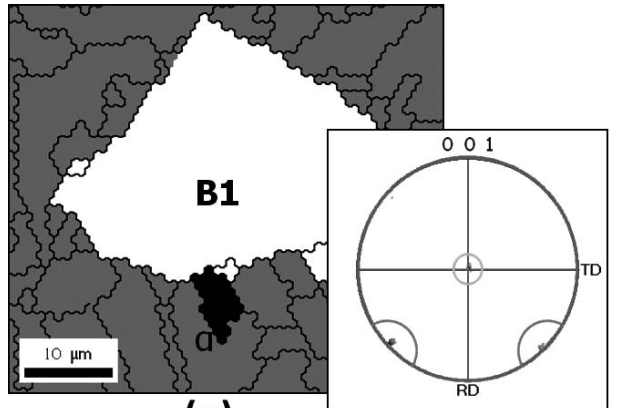

(a)

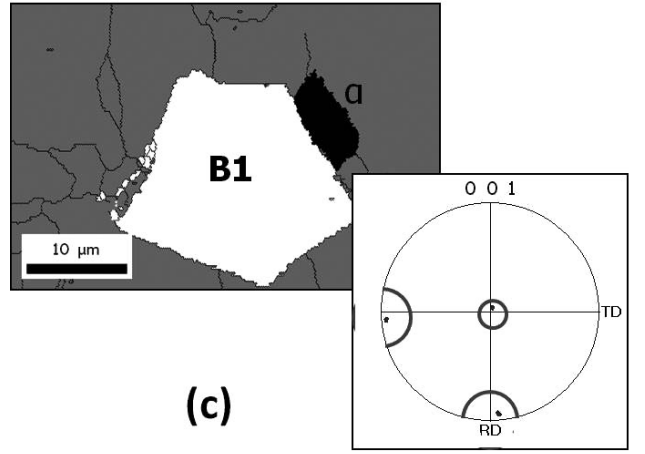

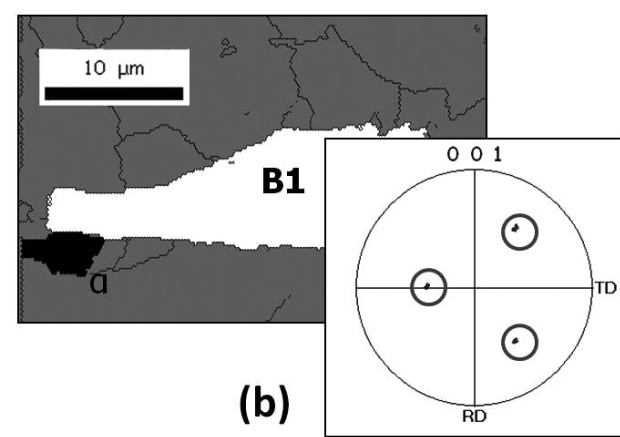

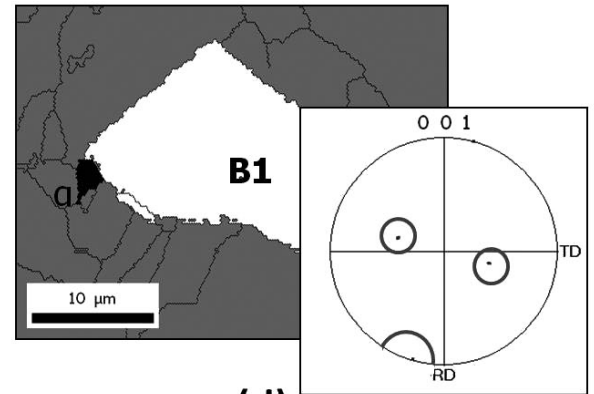

(d)

Fig. 3. (a) EBSD phase map and pole Figure of $\mathrm{Fe}(001)$. Circle area inside the pole figure stands for crystal orientation of ferrites having the Baker-Nutting orientation relationship $\left(\{100\}_{\mathrm{B} 1} / /\{100\}_{\alpha},<110>_{\mathrm{B} 1} / /<100>_{\alpha}\right)$ with B1 compounds under the condition that each 001 direction of $\mathrm{B} 1$ compounds are parallel to RD, TD and ND of this pole figure. (b) EBSD phase map and pole figure of a ferrite having orientation relationship $\{110\}_{\mathrm{B} 1} / /\{110\}_{\alpha},<100>_{\mathrm{B} 1} / /$ $\langle 110\rangle_{\alpha}$ (c) EBSD phase map and pole figure of a ferrite having orientation relationship $\{110\}_{\mathrm{B} 1} / /\{110\}_{\alpha},<100>_{\mathrm{B} 1} / /$ $<100>_{\alpha}$ (d) EBSD phase map and pole figure of a ferrite having orientation relationship $\{110\}_{\mathrm{B} 1} / /\{112\}_{\alpha},<100>_{\mathrm{B} 1} / /$ $<110>_{\alpha}$.

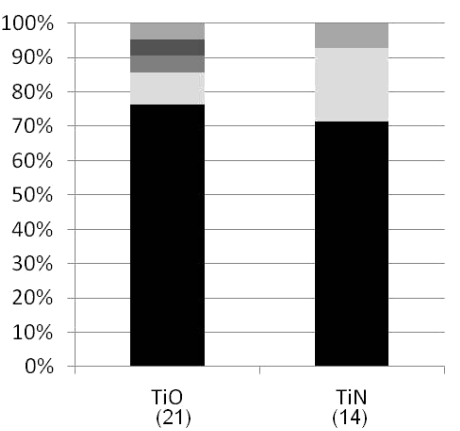

(a)

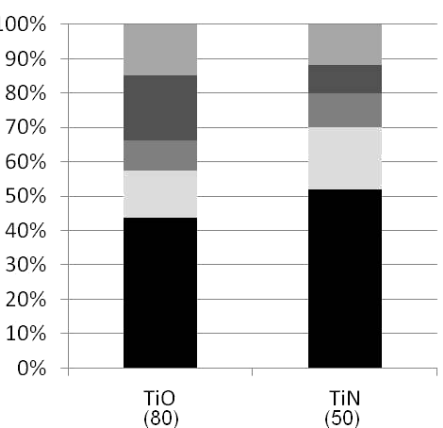

(b)

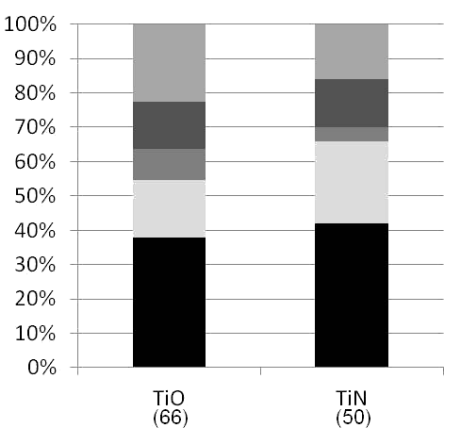

(c)

Others

$\{110\} B 1 / /\{112\} \alpha,<100>B 1 / /<110>\alpha$

$\{100\} \mathrm{B} 1 / /\{100\} \alpha,<100>\mathrm{B} 1 / /<100>\alpha$

$\{110\} B 1 / /\{110\} \alpha,<100>B 1 / /<110>\alpha$

Baker-Nutting OR

Fig. 4. Proportion of ferrites having some low index orientation relationships (OR) with $\mathrm{B} 1$ compounds (a) at $650^{\circ} \mathrm{C}(\mathrm{b})$ at $600^{\circ} \mathrm{C}(\mathrm{c})$ at $500^{\circ} \mathrm{C}$. The numbers of ferrites investigated by EBSD are indicated inside the Parentheses. 
with $\mathrm{TiN}$, which indicates that the B-N orientation relationship played a dominant role in the ferrite formation on those B1 compounds, and apparent difference between $\mathrm{TiO}$ and TiN was not observed at this temperature. As the transformation temperature decreased, the proportion of ferrites having the B-N orientation relationship decreased. As shown in Fig. 4(b), $45 \%$ and $52 \%$ of ferrites had the B-N orientation relationship with $\mathrm{TiO}$ and $\mathrm{TiN}$, respectively, and most of the ferrites without the B-N relationship had lowindex orientation relationships other than the B-N relationship. As the transformation temperature decreased further, the tendency became more prominent. That is, at $500^{\circ} \mathrm{C}$, only $38 \%$ and $42 \%$ of ferrites had the B-N orientation relationship with $\mathrm{TiO}$ and $\mathrm{TiN}$, respectively, and the proportion of other low-index orientation relationships increased as shown in Fig. 4(c). From Figs. 4(b) and 4(c), it is suggested that ferrite from TiN has a little more likely to have the B$\mathrm{N}$ orientation relationship than that from $\mathrm{TiO}$ at lower transformation temperatures.

The difference of ferrite formation behavior from $\mathrm{TiO}$ and TiN was confirmed clearly by quantitative analysis of misorientation angles from the exact B-N orientation relationship. In Fig. 5, ferrites having the B-N orientation relationship with the B1 compound of interest were classified by the misorientation angle from the exact B-N relationship. At the transformation temperature of $600^{\circ} \mathrm{C}, 72 \%$ of ferrites from TiN had misorientation angles less than 5 degrees, while only $26 \%$ from $\mathrm{TiO}$. At $500^{\circ} \mathrm{C}, 48 \%$ of ferrite from TiN had misorientation angles less than 5 degrees, while

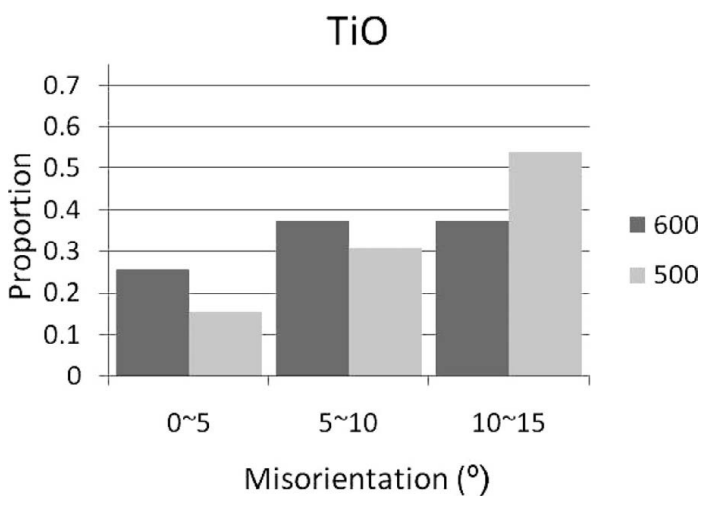

(a)

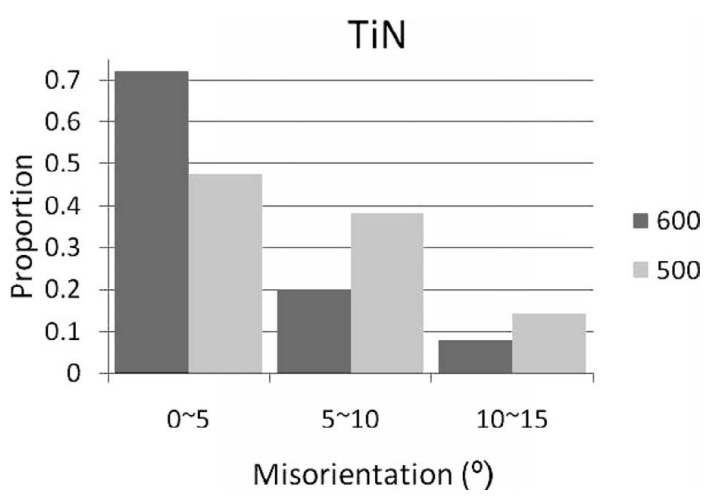

(b)

Fig. 5. Distribution of misorientation from the exact B-N orientation relationship between ferrite and (a) TiO (b) TiN. Bigger misorientation is allowed between ferrite and $\mathrm{TiO}$ than TiN and the misorientation increases as the transformation temperature decreases. only $15 \%$ from $\mathrm{TiO}$. It was demonstrated that ferrite can be nucleated with larger misorientation angle from $\mathrm{TiO}$ than from TiN, which is consistent with the result of the continuous cooling experiment conducted by Kasai et al. ${ }^{11)}$ It is also noted that there is a tendency that ferrites having larger misorientation angles increases as the transformation temperature decreases.

\subsection{Orientation Relationship between Prior Austenite and Ferrite}

For the nucleation of ferrite on a B1 compound, increase in interfacial energy caused not only by the ferrite/compound interface but also by the ferrite/austenite should be overcome. Thus, in this study, orientation relationship between ferrite and prior austenite was also investigated. Since Nagano and Enomoto reported that interface between ferrite and austenite has low interfacial energy when it has the Kurdjumov-Sachs (K-S) orientation relationship, ${ }^{13)}$ it was checked on the ferrites nucleating from B1 compounds.

It is well known that martensite and bainite have the $\mathrm{K}$ $\mathrm{S}$ orientation relationship with the prior austenite, and thus, it is possible to estimate the crystal orientation of the prior austenite grain by EBSD analysis based on the specific pattern of the K-S orientation relationship of martensite and bainite. Figures 6(a) and 6(b) are typical EBSD results showing (100) pole of the ferrite growing from TiO and TiN at $600^{\circ} \mathrm{C}$, respectively, as well as the $\mathrm{K}-\mathrm{S}$ relationship obtained from the surrounding microstructure. Figure 6(a) shows a ferrite that has a low-index orientation relationship with $\mathrm{TiO}$, other than the $\mathrm{B}-\mathrm{N}$ relationship, and at the same time, has the K-S relationship with the prior austenite. Figure 6(b) shows a ferrite having the B-N relationship with TiN but not having the K-S relationship with the prior austenite. Figures 6(c) and 6(d) are the examples of ferrite formed at $500^{\circ} \mathrm{C}$. Figure $6(\mathrm{c})$ shows a ferrite which has the B-N relationship with $\mathrm{TiO}$ and the K-S relationship with the prior austenite, and Fig. 6(d) a ferrite having the B-N relationship with TiN but without the K-S relationship with the prior austenite.

The number of ferrites having the K-S orientation relationship was almost negligible at the transformation temperature of $650^{\circ} \mathrm{C}$, but increased as the transformation temperature decreased, the tendency of which was different between $\mathrm{TiO}$ and TiN. The proportion of ferrites having the $\mathrm{K}-\mathrm{S}$ orientation relationship with prior austenite was $55 \%$ and $73 \%$ at $600{ }^{\circ} \mathrm{C}$ and $500^{\circ} \mathrm{C}$, respectively, in the case of $\mathrm{TiO}$, while it was $50 \%$ and $52 \%$ respectively at $600^{\circ} \mathrm{C}$ and $500^{\circ} \mathrm{C}$ in the case of TiN. Through the investigation in more detail, it was indicated that ferrites nucleated from B1 compounds without the B-N relationship tended to have the K$\mathrm{S}$ relationship with prior austenite. At the transformation temperature of $600^{\circ} \mathrm{C}$, among the ferrites having the B-N relationship with $\mathrm{TiO}$, only $28 \%$ had the $\mathrm{K}-\mathrm{S}$ relationship with prior austenite, while $77 \%$ had the K-S relationship when the ferrite did not hold the B-N relationship with TiO, as seen in Fig. 7(a). In case of TiN, 27\% of ferrites having the B-N relationship had the K-S relationship with prior austenite while $75 \%$ had the K-S relationship with prior austenite when the ferrite did not hold the B-N relationship. This result suggests that a low-index orientation relationship other than the B-N was selected to achieve lower total interfa- 


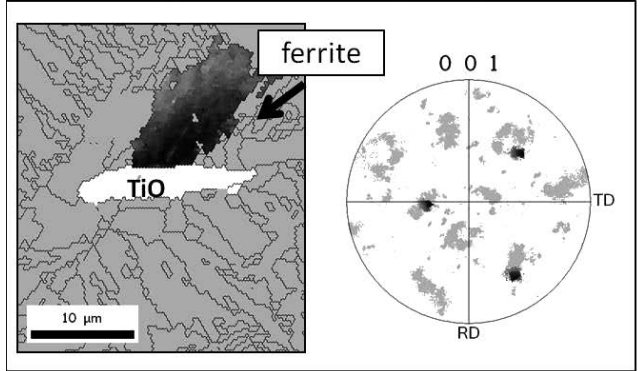

(a)

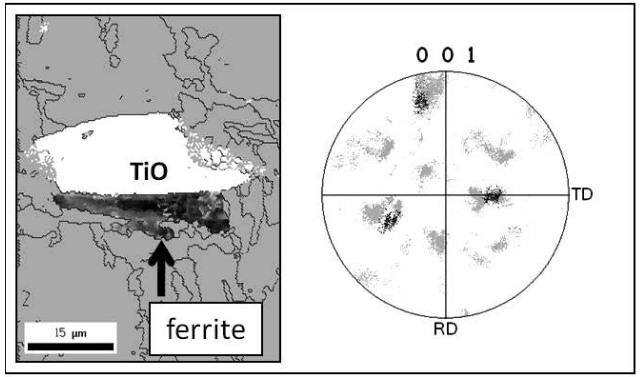

(c)

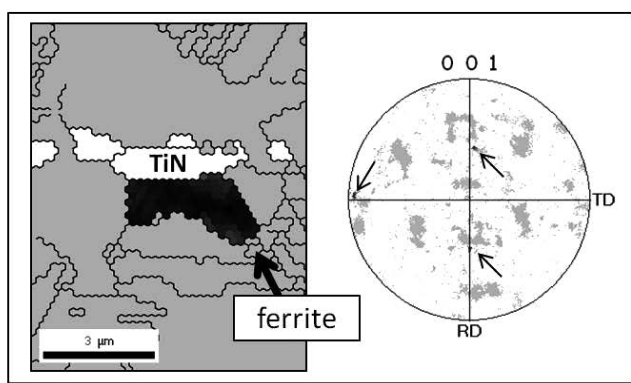

(b)
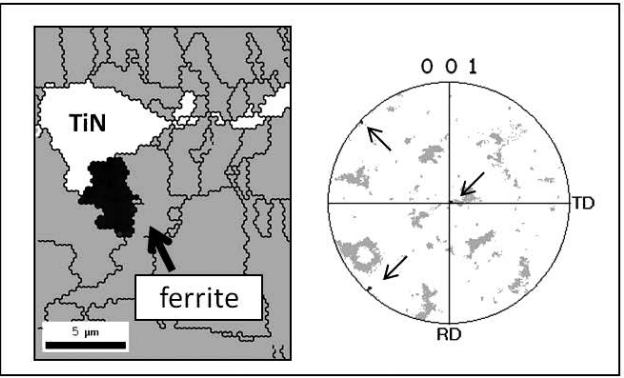

(d)

Fig. 6. Typical examples of ferrites according to B1 compounds and the transformation temperatures. (a) a ferrite having a low index orientation other than the $\mathrm{B}-\mathrm{N}$ orientation relationship with $\mathrm{TiO}$ and the $\mathrm{K}-\mathrm{S}$ orientation relationship with the prior austenite at $600^{\circ} \mathrm{C}(\mathrm{b})$ a ferrite having the $\mathrm{B}-\mathrm{N}$ orientation relationship with TiN but not having the $\mathrm{K}-\mathrm{S}$ orientation relationship with the prior austenite at $600^{\circ} \mathrm{C}(\mathrm{c})$ a ferrite having the B-N orientation relationship with $\mathrm{TiO}$ and the $\mathrm{K}-\mathrm{S}$ orientation relationship with the prior austenite at the same time at $500^{\circ} \mathrm{C}(\mathrm{d})$ a ferrite having the B-N orientation relationship with TiN and not having the K-S orientation relationship with the prior austenite at $500^{\circ} \mathrm{C}$.

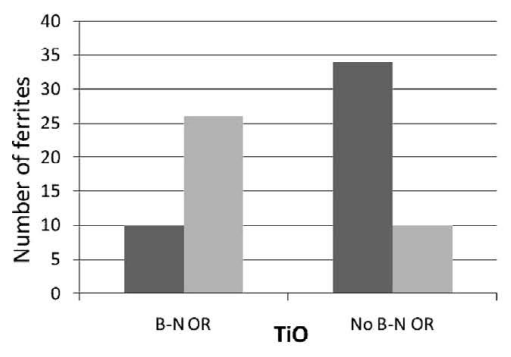

(a)

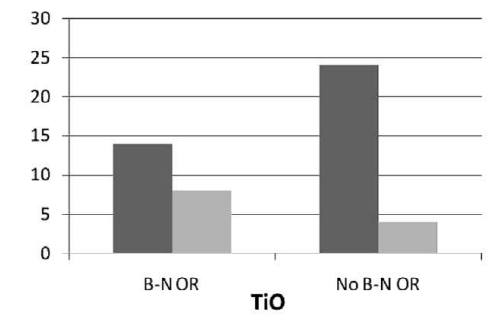

(c)

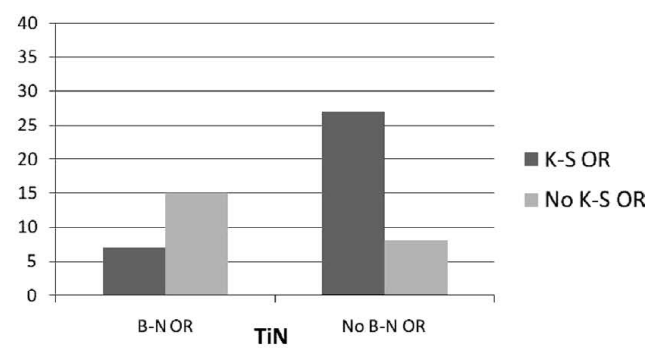

(b)

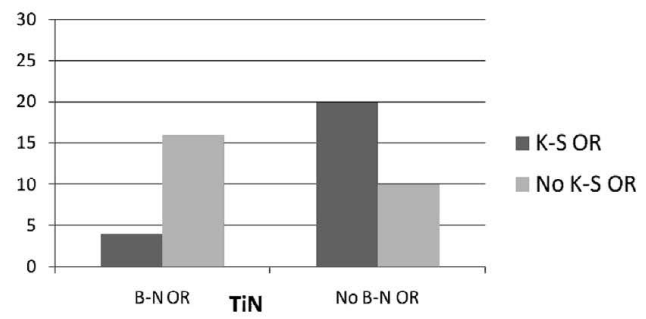

(d)

Fig. 7. Proportion of ferrites having the K-S orientation relationship (OR) with the prior austenite in the case that they have the B-N orientation relationship with B1 compounds and in the case that they do not (a), (b) At $600^{\circ} \mathrm{C}$, ferrites not having the B-N orientation relationship with $\mathrm{B} 1$ compounds tend to have the K-S orientation relationship with the prior austenite at this temperature. (c), (d) At $500^{\circ} \mathrm{C}$, differently from at $600^{\circ} \mathrm{C}$, ferrites of increased number had the B-N orientation relationship with $\mathrm{TiO}$ and the $\mathrm{K}-\mathrm{S}$ orientation relationship with the prior austenite at the same time. On the other hand, no big difference was observed for TiN compared to at $600^{\circ} \mathrm{C}$.

cial energy. At the lower transformation temperature, $500^{\circ} \mathrm{C}$, the fraction of ferrite having the $\mathrm{B}-\mathrm{N}$ orientation relationship with $\mathrm{TiO}$ and the $\mathrm{K}-\mathrm{S}$ relationship with prior austenite is increased, while the change is insignificant for TiN, as seen in Figures 7(c) and 7(d). This is probably because of the fact that larger misorientation angles are allowed for ferrite to nucleate from $\mathrm{TiO}$ at lower transformation temperatures. In fact, as in Fig. 8 showing the proportion of ferrites having the K-S orientation relationship with the prior austenite among ferrites having the B-N orientation relationship with B1 compounds according to their misorientation from the exact B-N orientation relationship, 
At $500^{\circ} \mathrm{C}$

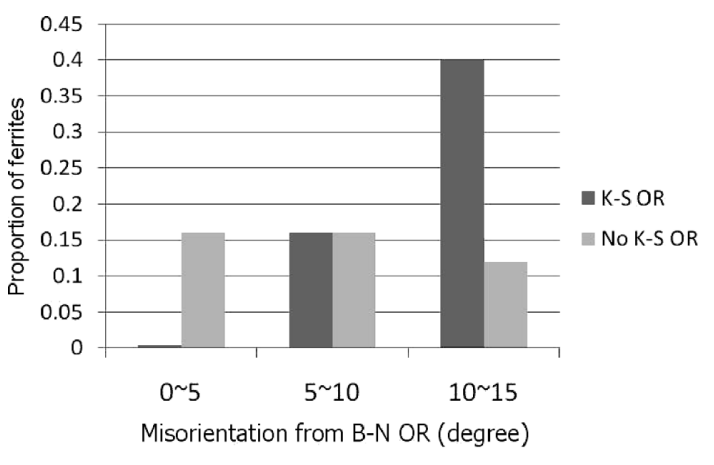

TiO

(a)

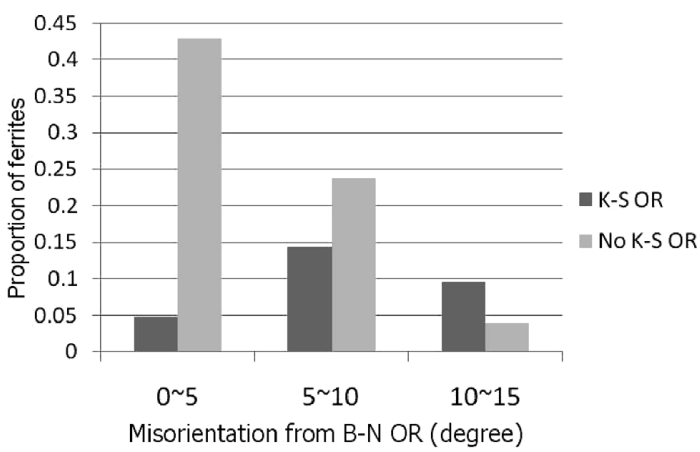

TiN

(b)

Fig. 8. Proportion of ferrites having the K-S orientation relationship (OR) with the prior austenite among ferrites having the B-N orientation relationship with B1 compounds according to their misorientation from the exact B-N orientation relationship. Ferrites of relatively big misorientation from the exact B-N orientation relationship tended to have the K-S orientation relationship with the prior austenite.

ferrites nucleating from B1 compounds with larger misorientation from the exact B-N orientation relationship achieved the K-S relationship with prior austenite.

\section{Conclusions}

From the isothermal austenite-to-ferrite transformation experiment conducted by embedding single crystalline grains of chemically pure B1 compounds in low-alloy steel, the following conclusions can be drawn:

(1) The Baker-Nutting orientation relationship plays a dominant role in ferrite formation from B1 compounds at $650^{\circ} \mathrm{C}$. The dependence of the Baker-Nutting orientation relationship decreases as the transformation temperature decreases. Instead, the Kurjumov-Sachs orientation relationship is more dominant than the Baker-Nutting orientation relationship.

(2) Ferrite nucleation from B1 compounds with lowindex orientation relationships other than the Baker-Nutting orientation relationship is also increased with decreasing transformation temperature. This leads to an increase in ferrite formation having the Kurdjumov-Sachs orientation relationship with prior austenite.

(3) Ferrites from $\mathrm{TiO}$ can have larger misorientation angles from the exact Baker-Nutting orientation relationship and thus tend to have the Kurdjumov-Sachs orientation relationship with prior austenite at lower transformation temperatures.

\section{REFERENCES}

1) T. Koseki and G. Thewlis: Mater. Sci. Technol., 21 (2005), 867.

2) D. S. Sarma, A. V. Karasev and P. G. Jönsson: ISIJ Int., 49 (2009), 1063.

3) A. R. Mills, G. Thewlis and J. A. Whiteman: Mater. Sci. Technol., 3 (1987), 1051.

4) B. L. Bramfitt: Metall. Trans., 1 (1970), 1987.

5) J.-S. Byun, J.-H. Shim, Y.-W. Cho and D.-N. Lee: Acta Mater., 51 (2003), 1593.

6) K. Yamamoto, T. Hasegawa and J. Takamura: ISIJ Int., 36 (1996), 80

7) J. M. Gregg and H. K. D. H. Bhadeshia: Acta Metall. Mater., 42 (1994), 3321.

8) S. Zhang, N. Hattori, M. Enomoto and T. Tarui: ISIJ Int., 36 (1996), 1301.

9) G. Shigesato, M. Sugiyama, S. Aihara and R. Uemori: Tetsu-to-Hagané, 87 (2001), 93.

10) C. Garcia-Mateo, C. Capdevila, F. G. Caballero and C. G. de Andrés: ISIJ Int., 48 (2008), 1270.

11) K. Kasai, C. -J. Lee, S. Nambu, J. Inoue and T. Koseki: Tetsu-toHagené, 96 (2010), 123.

12) D. Watanabe, J. R. Castles, A. Jostsons and A. S. Malin: Acta Cryst., 23 (1967), 307.

13) T. Nagano and M. Enomoto: Metall. Mater. Trans., 37A (2006), 929. 